\title{
La interculturalidad y la pragmática en el aula ELA
}

Cristina Simon ${ }^{*}$

Resumen: Este artículo de difusión pretende mostrar las bondades tanto de la aplicación metodológica del enfoque intercultural, como de la reflexión pragmática en las aulas de Español como lengua extranjera (ELA) del Centro de Enseñanza para Extranjeros (CEPE), esto como respuesta frente a los intentos unificadores de la era globalizadora en que vivimos.

Como vía concreta, se presenta la interesante propuesta del Instituto Cervantes en su Plan Curricular del año 2006, advirtiéndose sobre la necesidad de releerlo y adaptarlo a la específica realidad del español mexicano del altiplano central.

Palabras clave: Interculturalidad, globalización, pragmática, aula ELA.

Abstract: This article aims to show the benefits, spread both the methodological application of the intercultural approach as pragmatic reflection ELA classrooms of ECE, this as a response to attempts to unify the era of globalization in which we live.

As a concrete way, presents the interesting proposal of the Instituto Cervantes Curricular Plan of 2006, noting the need to reread it and adapt to the specific circumstances of the central highland Mexican Spanish.

Keywords:: Multiculturalism, globalization, pragmatics, ELA classroom.

\begin{abstract}
* Licenciada en Filología Hispánica por la Universidad de Málaga, España, Maestra en Letras (Literatura Mexicana) por la Universidad Nacional Autónoma de México y actual aspirante al Doctorado en Lingüística Aplicada en esta misma casa de estudios. Profesora de ELA en el Centro de Enseñanza para Extranjeros de la UNAM desde hace 25 años y profesora de historia del español y de dialectología hispánica en la Especialización de Profesores de Español como LE. Mi área de interés es la lengua en cualesquiera de sus abordajes; actualmente, está concentrada en la disciplina pragmática, tanto en su reflexión teórica como en su aplicación práctica en el aula de elA.
\end{abstract}

1 ELA: Español como lengua adicional. Comprende, tanto L2 (segunda lengua), como LE (lengua extranjera). 
ENFOQUE INTERCULTURAL

\section{La interculturalidad en el diálogo con lo ajeno}

En la consideración de los diálogos entre culturas diferentes, el enfoque intercultural es un muy deseable punto de partida, tal como quedó expresado por Arturo Quispe en la entrevista que le realizó a dos importantes ideólogos de la interculturalidad en América — los maestros Fidel Tubino y Gonzalo Portocarrero.

La interculturalidad como enfoque analítico, como apuesta política y entendida en su sentido más amplio tiene, cada vez, mayor acogida en muchos países, ya que plantea una propuesta de diálogo horizontal que resulta enriquecedor y deseable entre diversas culturas.

En efecto, en esta época de globalización, la propuesta intercultural resulta harto seductora, ya que parte de la premisa de que lengua y cultura son un binomio indisociable, lo que le otorga a los individuos un sentimiento de pertenencia identitaria.

Además, como precisó el Dr. Gonzalo Portocarrero en la misma entrevista, "tiene el añadido de que es algo por hacer, por teorizar aunque existan actitudes que están en la base del concepto como las críticas al etnocentrismo, el elogio de la tolerancia y la creencia en la diversidad" que, necesariamente, se construye todos los días tanto, y sobre todo, en nuestras actitudes cotidianas como en nuestras investigaciones.

En mi campo de acción, las tendencias actuales de la enseñanza-aprendizaje de LA se han adscrito, desde hace algunas décadas, al área académica conocida como comunicación intercultural. Son varios los lingüistas —pertenecientes a diferentes escuelas y con diversos abordajes - que desde esta perspectiva consideran como hecho incuestionable que el aprendizaje de una lengua está unido a la comprensión de la cultura de la cual esa lengua es portadora. Así, cuando alguien aprende otro idioma adquiere experiencia y asimila algo de una o más sociedades distintas a la suya y a sus prácticas culturales.

Este interés por la dimensión cultural del aprendizaje de idiomas permitió abandonar el excesivo énfasis en la gramática que se había hecho desde el Estructuralismo, con la finalidad de favorecer el desarrollo de la competencia comunicativa ${ }^{2}$ y promover un diálogo menos malentendido y prejuicioso entre las culturas que entran en contacto durante dicho proceso.

2 Se sigue la propuesta del Marco Común de Referencia Europeo (MCRE), por tanto, se entenderá por competencia comunitiva el conjunto de destrezas que posibilitan a una persona para actuar lingüísticamente en sociedad. Ésta se constituye a partir de tres competencias: lingüística, sociolingüística y pragmática. 
Ahora bien, para acercarnos a este objetivo es fundamental resaltar que, a menudo, las palabras aparentemente más inocentes y los actos verbales ${ }^{3}$ más simples pueden encerrar un significado diferente y una distinta concepción y codificación lingüística, según la particular construcción del mundo que cada cultura lleve a cabo.

$Y$ es que, como se desprende de lo anterior, las lenguas no son únicamente un medio para referirse al mundo objetivo que nos rodea, ya que también constituyen connotaciones compartidas que ayudan al hablante a mantener su sensación de pertenencia a cierto grupo cultural y social. No obstante, cuando uno de los participantes en el diálogo es extranjero, esta afirmación se relativiza, debido a que no es posible asegurar que sean partícipes de dichas connotaciones.

Como se mencionó, lengua y cultura son, desde la perpectiva intercultural, entes indisociables y su puesta en práctica en el proceso de enseñanza-aprendizaje de LA favorece enormemente la comprensión de dicho binomio dentro de la cotidianeidad de los involucrados en el proceso, lo que conlleva resultados más genuinos.

\section{La interculturalidad frente a la globalización}

Ahora bien, independientemente de cómo haya sido la consideración directa sobre el binomio lengua y cultura a lo largo de la historia en Occidente, la propuesta intercultural —Fidel Tubino y Gonzalo Portocarreño— de un diálogo respetuoso y horizontal entre las otredades o alteridades es novedosa y deseable, ya que no se plantea restar en aras de la uniformidad y del pensamiento unánime, sino, más bien, multiplicar para favorecer la riqueza de la diversidad cultural.

Piénsese en cómo, ya sea remitiéndonos al feroz monoteísmo propugnado por el judeocristianismo — como lo señala, entre otros, el ecologista y teólogo de la liberación Leonardo Boff (1997) —, ya a la glotofagia occidental —en este caso, siguiendo la perspectiva de Calvet $^{5}$ (2005)—, vivimos una época de peculiar e indiscutible intolerancia hacia la diversidad: la imposición de la globalización es sinónimo de imposición del pensamiento unánime.

Nihil novum sub solem.

En efecto, en la historia del mundo se ha repetido la circunstancia de que cada descubrimiento y cada diálogo con lo ajeno impulsa a las comunidades a (re)pensar sus vínculos, lo que provoca que algunas teoricen su superioridad sobre las demás.

3 Vistos desde la perspectiva del filósofo inglés John Austin (1960), precisados por su discípulo John Searle (1972), y releídos por Haverkate (1994).

4 Genésio Darci Boff, en su vida de lego.

5 E. Payot (1974) Linguistique et colonialisme. Petit traitè de glottophagie, En este comunicado se seguirá la versión del Fondo de Cultura Económica. 
Concretamente, en la herencia del pensamiento occidental -parte innegable de nuestra adscripción como mexicanos-, la derivación política del monoteísmo dio la legitimación a los regímenes autoritarios y totalitaristas ya que -en la más lineal de las lecturas_-, si sólo hay un Dios, debe haber un solo representante del mismo en la tierra y, por ende, una única verdad y un único pueblo como portador de la misma.

Esta linealidad del pensamiento monoteísta occidental rompió cualquier posibilidad de diálogo horizontal con la otredad y cualquier construcción equitativa dentro de la diversidad humana. Por su parte, impregnada de un claro destino manifiesto, la tradición judeocristiana ha tenido siempre una justificación para todas sus empresas guerreras ya que, en el Génesis —capítulo 1, versículo 28-, Moisés, textualmente, pone en boca de Jeohvá las siguientes y definitivas palabras:

Fructificad y multiplicaos; llenad la tierra y sojuzgadla ${ }^{6}$ y señoread en los peces del mar, en las aves de los cielos, y en todas las bestias que se mueven sobre la tierra.

Ante tamaño des(a)tino, y concretamente en lo que respecta a la consideración de la lengua, no es difícil entonces comprender cómo, regresando nuevamente a Calvet (2006), la cultura occidental ha sido muy proclive a la glotofagia (del griego glota, "lengua" y phagos, "comer"), al lingüicidio o al genocidio lingüístico, entendiendo por ello el proceso político-social mediante el cual el idioma de una determinada cultura desaparece parcial o totalmente, al ser víctima de la influencia directa y coercitiva de otra lengua y de otra civilización que se pretenden superiores. Dicha superioridad les proporciona la legitimidad necesaria para sobreponerse a las demás y, en el terreno del lenguaje, desaparecerlo, hecho que se hace evidente en diversos momentos de la historia y, especificamente, en las conquistas y colonizaciones de América. El año de 1492 representa, entonces, el inicio de la llamada glotofagia europea contra los habitantes autóctonos de las tierras americanas tanto insulares como continentales: innumerables lenguas y culturas desaparecieron de cuajo o fueron condenadas a una lenta e irremediable agonía.

Sin embargo, es justo señalar que no todas las lenguas autóctonas americanas corrieron la misma suerte; mientras algunas, por ejemplo, el quechua -o quechuaimara como precisan algunos lingüistas - y el náhuatl fueron consideradas como generales y mantuvieron una relativa dosis de vitalidad que ha llegado hasta nuestros días; otras, por su parte, no pudieron soportar el embate europeo y sus hablantes terminaron suicidándose colectivamente en el más romántico y terrible de los pactos sociales, tal fue el caso de los arahuaco-taínos, cuyas lenguas son, curiosamente, las que más palabras aportaron al léxico patrimonial del español general.

6 El subrayado es mío. 
Sea como sea, la glotofagia implica, indudablemente, una imposición colonialista sin posibilidad alguna de negociación con las culturas conquistadas, las cuales están condenadas desde el poder.

Ante la realidad histórica, el único camino justo en las políticas lingüísticas de los actuales estados nacionales está en el enfoque intercultural, donde se busca, principalmente, un diálogo horizontal, respetuoso y genuino entre todas las lenguas y culturas que conforman las complejas y variadas naciones americanas, ya que no debemos perder de vista que, tras el triunfo de los movimientos independentistas, la suerte de las civilizaciones y de los idiomas autóctonos de este continente no ha cambiado sustancialmente. Cabe destacar que ha habido - y sigue habiéndo- loables y diferentes (como diversas son las naciones que nos conforman) proyectos, aunque con éxitos parciales, debido a que la postura glotófaga de la mayoría de los estados nacionales actuales se repite nuevamente en gran parte de nuestra realidad cotidiana. Así, el reconocimiento de nuestra diversidad sigue estando caracterizado por el desencuentro y la imposición.

Con respecto a lo anterior, los maestros de ELA del CEPE tenemos la oportunidad de contribuir, aunque sea modestamente, en la puesta en práctica de nuevas metodologías para entablar diálogos interculturales - más respetuosos y genuinos- entre las lenguas que están en contacto en nuestras aulas, sin favorecer o desdeñar ninguna de ellas. Además, tenemos la posibilidad de insistir en la riqueza enorme del español y de reflexionar y mostrar la variante lingüística del español del altiplano central mexicano frente a otras variantes igualmente ricas, como la castellana.

\section{La Pragmática}

Para lograr lo anterior, ha entrado en juego una nueva disciplina: la pragmática. Ésta es una de las nuevas ramas de la lingüística, cuyo nacimiento puede situarse, entre otras opiniones, en el año 1938, gracias a la concepción triádica de la semiótica ideada por el filósofo Charles Morris. Siguiendo a Alcaraz (1996: 25), en el esquema morrisiano de análisis de la lengua "se percibe un signo un designatum y un usuario o intérprete, y entre ellos se desarrolla una triple relación, que él llama la sintáctica, la semántica y la pragmática".

Esta tripartición dio origen a la distinción entre sistema y uso de la lengua, y permitió determinar el límite entre la semántica — ¿qué significa x? — y la pragmática - ¿qué es lo que alguien quiere decir cuando usa $x$ ? Una vez establecida la distinción, la novel disciplina se enfrentó con uno de los problemas más complejos y difíciles de aprender en esta nueva teoría de la comunicación: la interpretación 
del oyente sobre la intención del hablante, con la complicación añadida de que el significado pragmático está regulado por principios que determinan los comportamientos sociales de los participantes en la situación comunicativa.

Así, la pragmática reflexiona sobre los aspectos extralingüísticos de la comunicación verbal, los cuales condicionan nuestro uso cotidiano de la lengua y proponen un análisis del contexto en la interpretación del significado, dado que éste no es siempre unívoco como se ejemplifica en el siguiente texto de Voltaire. ${ }^{7}$

\section{Cuando un diplomático dice sí, quiere decir "quizás"; \\ cuando dice quizás quiere decir "no" \\ y cuando dice no, no es un diplomático. \\ Cuando una dama dice no, quiere decir "quizás", \\ cuando dice quizás quiere decir "si" \\ y cuando dice sí, no es una dama.}

En efecto, en esta cita se ejemplifica claramente cómo los significados convencionales - los semánticos- no siempre son los que funcionan en la comunicación verbal. Entonces, ¿cuáles son los mecanismos que intervienen para que una misma palabra - quizás, sí, no - tenga sentidos opuestos?, ¿qué ocurre cuando, además del significado semántico, actúan los hablantes, la intención ilocutiva de los mismos, la situación de habla, el tiempo, el espacio, y surgen diferentes contenidos a los semánticos? Pues bien, el estudio de éstos y otros problemas queda en el dominio de la pragmática que, por primer vez desde hace muchísimo tiempo, se ha interesado por el modo en que el contexto influye en la interpretación del significado, entendiéndose el contexto en su sentido más amplio, y pudiéndose de esta manera incluir cualquier aspecto extralingüístico: situación comunicativa, conocimiento compartido por los hablantes, relaciones interpersonales, etcétera. La pragmática, entonces, toma en consideración los factores que condicionan indefectiblemente el uso de la lengua y a los que no se refieren en un estudio puramente formal: 8

$Y$ es que, como se comentó en el primer apartado, siempre que se entablan relaciones entre personas de diferentes lenguas -o incluso, de la misma, aunque de diversas variantes dialectales-, paralelamente, se establecen diálogos interculturales. Al respecto, vale la pena que nos detengamos en el siguiente fragmento que abre el libro de crónicas africanas, Ébano (2001: 22-23), del gran

7 Citado por Escandell (2008), en Introducción a la pragmática.

8 No obstante, la pragmática no puede prescindir ni de la sintaxis, ni de la semántica porque, "es prácticamente imposible interpretar un mensaje si no se conocen las relaciones que los signos guardan entre sí, ni las que mantienen con el mundo al que hacen referencia" (Alcaraz,1996: 26). 
periodista y humanista polaco Ryszard Kapuscinsky. En éste se ilustra la visión cultural del abordaje —y por ende, el tratamiento- del tiempo entre los continentes europeo y africano:

\section{Camino de Kumasi}

Nos subimos al autobús y ocupamos los asientos. En ese momento puede producirse una colisión entre dos culturas, un choque, un conflicto. Esto sucederá si el pasajero es un forastero que no conoce África. Alguien así empezará a removerse en el asiento. a mirar en todas direcciones y a preguntar: "¿Cuándo arrancará el autobús?" ¿Cómo que cuándo?", le responderá el conductor, "cuando se reúna la gente que lo llene del todo".

El europeo y el africano tienen un sentido del tiempo completamente diferente; lo perciben de maneras dispares y sus actitudes también son distintas. Los europeos están convencidos de que el tiempo funciona independientemente del hombre, de que su existencia es objetiva, en cierto modo exterior, de que se halla fuera de nosotros y de que sus parámetros son medibles y lineales. Según Newton, el tiempo es absoluto: "Absoluto, lineal y matemático, el tiempo transcurre por sí mismo y, gracias a su naturaleza, transcurre uniforme y no en función de alguna cosa exterior." El europeo se siente como su siervo, depende de él, es su súbdito. Para existir y funcionar, tiene que observar todas sus férreas e inexorables leyes, sus encorsetados principios y reglas. Tiene que respetar plazos, fechas, días y horas. Se mueve dentro de los engranajes del tiempo; no puede existir fuera de ellos. Y ellos le imponen su rigor, sus normas y sus exigencias. Entre el hombre y el tiempo se produce un conflicto insalvable, conflicto que siempre acaba con la derrota del hombre; el tiempo lo aniquila.

Los hombres del lugar, los africanos, perciben el tiempo de manera bien diferente. Para ellos, el tiempo es una categoría mucho más holgada, abierta, elástica y subjetiva. Es el hombre el que influye sobre la horma del tiempo, sobre su ritmo y su transcurso (por supuesto, sólo aquel que obra con el visto bueno de los antepasados y de los dioses). El tiempo, incluso, es algo que el hombre puede crear pues, por ejemplo, la existencia del tiempo se manifiesta a través de los acontecimientos, y el hecho de que un acontecimiento se produzca o no, depende sólo del hombre.

Todo lo contrario de la manera de pensar europea.

Traducido a la práctica, eso significa que si vamos a una aldea en donde, por la tarde, debería celebrarse una reunión y allí no hay nadie, no tiene sentido la pregunta: ¿Cuándo se celebrará la reunión?" La respuesta se conoce de antemano: "Cuando acuda la gente".

Diferencias como ésta suelen provocar malentendidos culturales, las más de las veces ofensivos, ya que son interpretados como afrentas a la imagen social ${ }^{9}$ de los participantes quienes, en pleno siglo xxı, seguimos acudiendo a la manida explicación de estereotipos que suelen separar a los pueblos, en lugar de unirlos.

9 Noción tomada de Goffman (1959) que se refiere a la construcción social del individuo. 
Los motivos de estos desencuentros culturales no siempre son fáciles de identificar - y, por ende, de abordar-, dado que no ocurren a causa de un deficiente o mal manejo de la competencia lingüística, sino por el desconocimiento de ciertas claves culturales. o bien, por la interferencia con los de la cultura propia; es decir, el motivo de muchísimos choques estriba en la incomprensión o el uso inadecuado de la competencia pragmática ${ }^{10}$ de los participantes, la cual es más compleja y difícil de aprender que la lingüística.

Volviendo a mi realidad, al enseñar a una población fundamentalmente heterogénea de estudiantes, dichos choques son cotidianos, aunque no insuperables. Asimismo, los aportes con los que la pragmática ha enriquecido el área de enseñanza de lenguas no son en absoluto desdeñables.

De hecho, las contribuciones de esta disciplina se han revelado como excelentes medios para alcanzar el objetivo propuesto por el enfoque intercultural, en el sentido de lograr entablar un diálogo menos prejuicioso y genuino entre las culturas que están en contacto.

EL AULA DE ELA

Planteamiento del problema

En mi calidad de extracontinental en México, vine, vi y me maravillé. Muchas veces comprendía lo que decía la gente, sin entender lo que quería decir.

Estas certeras y vigentes palabras de la Dra. Marlene Rall ilustran perfectamente uno de los problemas cotidianos de los alumnos en el aula de ELA: comprender sin entender.

$Y$ es que, como hemos señalado, las dificultades más graves de incomprensión -o de ruptura - en los diálogos interculturales ocurren por el desconocimiento del nivel pragmático de la lengua meta o por las interferencias con el del lenguaje materno. Éste es un problema todavía muy poco comprendido y. peor aún, no se ha trabajado de manera institucional en las aulas del CEPE.

Cuántas veces en el diálogo intercultural en dichas aulas no hemos sabido interpretar adecuadamente $y$, en consecuencia, actuar, por ejemplo, las respuestas de alumnos orientales, específicamente japoneses, frente a determinados ofrecimientos nuestros. Obsérvese la secuencia tomada de una mis notas de clase: 
—Junco: Perdón maestra, lo siento mucho; gracias, es usted muy amable.

En este punto, la disciplina pragmática se hace presente, puesto que por ella es posible comprender nuestra extrañeza ante respuestas como la del ejemplo, las cuales se deben a una manera distinta de entender y de fijar lingüísticamente la expresión de agradecimiento entre el español y el japonés, Para este último, el mencionado acto de agradecer se formula mediante dos acciones de habla diferentes: una disculpa previa por la molestia ocasionada al interlocutor (perdón, lo siento mucho) y, posteriormente, el dar las gracias.

Ante este planteamiento, resulta natural aceptar que apropiarse de una LA no significa únicamente lograr una competencia gramatical adecuada, sino también adquirir una apropiada competencia pragmática, ya que en el proceso de enseñanza-aprendizaje ésta se ubica en las lindes socio-pragmáticas donde ocurren más choques culturales. Un ejemplo de lo anterior podría ser cuando un extranjero no hispanohablante comete un error gramatical al confudir el uso de los verbos ser y estar (Yo estoy de Japón), ante esto su interlocutor suele ser benevolente y comprensivo; sin embargo, si éste incurre en una incorrección de tipo pragmático, la reacción del mismo interlocutor es casi siempre negativa, ya que daña su imagen y conduce, la mayoría de las veces, a la ruptura de la comunicación y al refuerzo de los estereotipos que, como hemos señalado, tanto perturban y estorban el diálogo intercultural.

Para incidir positivamente en el proceso de enseñaza-aprendizaje de $L A$, se debe comprender que la formulación de los actos de habla no es universal, puesto que también revela un concreto y específico cúmulo de connotaciones culturales que comparten los miembros de una comunidad lingüística, los cuales difieren de una a otra, incluso, tratándose de la misma lengua.

\section{Un ejemplo evidente: La cortesía verbal}

Se ha elegido el fenómeno de la cortesía, específicamente, la verbal, ya que es uno de los campos en los que dichos choques o desencuentros culturales resultan más frecuentes y peligrosos. Téngase en cuenta los problemas que ocasiona el desconocimiento mutuo de estrategias negociadoras en diálogos interculturales que giran alrededor de invitaciones, por ejemplo. Independientemente de haber vivido en carne propia situaciones muy similares — sobre todo por el uso tan frecuente de la expresión "a ver cuándo nos vemos" que, simplemente, manifiesta cordialidad en México, pero que no suele ser entendida así por muchos estudiantes no hispanohablantes del CEPE-; a continuación cito un 
diálogo entre un estadounidense (E) y un israelita (I) (Blum-Kulka, 1996: 156), que ilustra muy bien el desencuentro del que hablamos:

-E: We really should get together for lunch.

-l: Yes, fine. Are you free tomorrow?

-E: No, tomorrow is awful. I'll call you, okay?

-l: Okay (puzzled and slightly ofended).

Lo anterior refleja un diálogo fallido, a pesar de que la cortesía es un hecho universal, pues hasta el momento no se ha encontrado una cultura donde no existan muestras de comportamiento cortés. No obstante, la manera en que cada civilización la considera, la define y la codifica no es absoluta, ya que lo que se percibe como afable en una puede resultar extraño o totalmente inapropiado en otra, incluso, impertinente. De ahí se derivan los continuos desencuentros en los actos comunicativos interculturales que tiene ocasión en el proceso de adquisición de cualquier lenguaje adicional. Asimismo, Haverkate (1994) afirma:

Aunque la cortesía se considera como una forma de comportamiento humano, es sabido que existe una serie de diferencias interculturales en lo que no sólo respecta a la manifestación formal, sino también a la función interactiva de las normas vigentes en cada cultura específica (12).

Aunado a lo expresado y para resaltar aún más la envergadura del problema, así como la necesidad de contribuir a su solución, debe tenerse en cuenta que esta situación no es privativa de diálogos interculturales entre individuos de diferentes lenguas; piénsese en los choques habidos entre españoles y mexicanos en este resbaladizo terreno y baste, como muestra, el siguiente par de textos.

Por una parte, el magnífico y vigente texto del maestro Ángel Rosenblat EI castellano de España y el castellano de América ${ }^{11}$, el cual inicia con esta reveladora afirmación, muy en la línea del problema que nos ocupa:

Ha dicho Bernard Shaw que Inglaterra y Estados Unidos están separados por la lengua común. Yo no sé si puede afirmarse lo mismo de España e Hispanoamérica. Pero de todos modos [...]

Después de esta entrada, el lingüista venezolano, poniendo a dialogar en clave de humor las voces de un turista, de un lingüista y de un filólogo, inicia así:

11 Este mismo fragmento, trabajado didácticamente, aparece en el manual de nivel Superior de la serie Así hablamos. Español como lengua extanjera coordinado por mí, con excelentes resultados en el aula. 
Visión del turista. El turista en Méjico ${ }^{12}$

Detengámonos en la visión del turista. Un español que ha pasado muchos años en los Estados Unidos lidiando infructuosamente con el inglés, decide irse a Méjico, porque allá se habla español, que es, como todo el mundo sabe, lo cómodo y lo natural. En seguida se lleva sus sorpresas. En el desayuno le ofrecen bolillos ¿Será una especialidad mexicana? Son humildes panecillos que no hay que confundir con las teleras y aun debe uno saber que en Guadalajara los Ilaman virotes y en Veracruz, cojinillos [...]

Pero las diferencias no se restringen únicamente al plano meramente léxico; más adelante, tocando ya específicamente el punto que nos interesa, relata Rosenblat:

Le han ponderado la exquisita cortesía mejicana, y tiene ocasión de comprobarlo:

- ¿Le gusta la paella?

- !Claro que sí! La duda ofende.

— Pos si no tiene inconveniente, comemos una en la casa de usted.

No podía tener inconveniente, pero le sorprendía que los demás se convidaran tan sueltos de cuerpo. Encargó en su hotel una soberbia paella, y se sentó a esperar. Pero en vano, porque los amigos también lo esperaban a él en la casa de usted, que es la de ellos [...]

Su casa (o el más pleonástico y popular su casa de usted) es una de las expresiones corteses que más confusiones y malos entendidos provoca en los diálogos interculturales en México y, aunque ésta haya sido herencia directa del refinamiento árabe, su uso en nuestro país parece hundir sus raíces en nuestra especial conformación del tipo de cortesía y en nuestra - excesiva para otras culturas- concreta codificación verbal cortés.

Por otra parte, el segundo texto del escritor mexicano Jorge Ibargüengoitia $(1990)^{13}$ expone lo siguiente en una de sus más que divertidas crónicas: ${ }^{14}$

Sin embargo, la hospitalidad mexicana real, la verdadera, que es parte de la cortesía mexicana, es algo muy distinto, que merece una seria reflexión [...]

Creo que la culminación de la hospitalidad mexicana es la sustitución de la frase "mi casa", por "la casa de usted". Cómo se llegó a esa sustitución es para mí un misterio.

12 Se le recuerda al amable lector que escribir Méjico con /j/ era algo común entre los hispanistas de la época.

13 Cito por la compilación de Guillermo Sheridan, Instrucciones para vivir en México (1990), que reúne crónicas publicadas en el peródico Éxcelsior entre 1969 y 1976.

14 Se trata, concretamente. de la titulada "Hospitalidad mexicana. La casa de usted,.(1990, 76-78), asimismo, usada en el mencionado manual de ELA superior tras el correspondiente trabajo didáctico. 
Durante un tiempo pensé que tenía por objeto responsabilizar al invitado. En efecto, al decirle alguien "está usted en su casa", estamos - hasta cierto puntohaciendo responsable al recién llegado de lo que pase en ella. El defecto de esta teoría es que la expresión "la casa de usted" a la que se anteponen los adjetivos "pobre" o "humilde" se usa, en la mayoría de los casos, en un contexto que nada tiene que ver con una invitación. Se usa, por ejemplo, en la narrativa:

- Cuando salí de la humilde casa de usted, estaba lloviendo a cántaros.

- En la pobre casa de usted, tenemos tres perros.

Cuando hay invitación es en términos tan vagos que queda invalidada:

- Un día de éstos, cuando haya oportunidad, quiero que venga usted a su humilde casa a probar un molito que hace mi mujer.

Cuando alguien nos dice esto, ya sabemos que el molito se va a quedar platicado.

Es posible que el término que nos ocupa no se use en las invitaciones por las confusiones que podría provocar. Si decimos, por ejemplo, una frase como la siguiente:

- ¿Qué le parece si esta noche cenamos en su humilde casa?

Corremos el riesgo de que la persona a quien estamos invitando tan amablemente nos conteste algo como esto:

- ¿En mi casa? ¡Ni hablar!

O bien:

- Mire, señor, mi casa es humilde, pero no tanto como la de usted.

Que es ya el colmo de la confusión, porque no sabemos si el que nos dice eso está insultándonos, o siendo ultracortés.

Ambos textos ilustran la magnitud del problema expuesto y provocan dudas sobre la posibilidad de manejarlo en el aula de ELA. De hecho, son los menos los manuales de ELA, tanto peninsulares como mexicanos, que lo manejen de forma sistemática.

\section{DifICULTADES PARA ABORDAR EL FENÓMENO PRAGMÁTICO EN EL AULA DE ELA}

Y es que, si se revisan las causas que dificultan el abordaje del uso lingüístico, podremos comprender el loop en el que la teoría está inmersa y que se refleja en dos problemas fundamentales.

Con respecto al fenómeno de la cortesía verbal, lo primero que debe señarlarse es la inexistencia de un consenso en el abordaje del mismo: saber para algunos, norma para otros, comportamiento social para algunos más. Esto es grave, ya que el modo de introducción en la metodología del proceso de enseñanza-aprendizaje y la orientación del los materiales didácticos que se construyan para tal fin dependerán de la postura que asuma el profesor.

Ante este aparente callejón sin salida, en el 2006 apareció el Plan Curricular del Instituto Cervantes (PCIC desde ahora) con una novedosa propuesta: considerar el fenómeno de la cortesía verbal como un conjunto de estrategias y técnicas prag- 
máticas $\mathrm{y}$, haciéndonos un guiño a los profesores de ELA, nos presenta un inventario sistematizado taxonómicamente y organizado según el Marco Común de Referencia Europeo (mCRE desde ahora), asimismo, en "aras de una rentabilidad pedagógica" plantea una perspectiva integradora y generalista, como se ahondará en las siguientes líneas.

Ahora bien, también resulta preciso señalar que si se le considera un conjunto de reglas (éstas se pueden enseñar/aprender/aplicar) será más fácil su introducción en el aula, pero si se le toma como una estrategia será más difícil, ya que el éxito o fracaso de la misma dependerá de muchísimos factores versátiles, imposibles de sistematizar.

Entonces, surge otro problemas, ya que, como se ve, la cortesía verbal es un fenómeno con tres ejes básicos de variación -intercultural, intracultural y personal-, cada uno de los cuales está subdividido en innumerables apartados, lo que acarrea la imposibilidad de identificar un único patrón modélico en el cual apoyarnos. A continuación, mostramos a algunos de los elementos que conforman cada uno de los mencionados ejes.

En cuanto a la variación intercultural, los desfases atañen, entre otros, a las peculiares formas lingüísticas usadas para la cortesía, a los significados y a la valoración social que se atribuye a una misma estrategia afable, a la preferencia y frecuencia en el uso de dichas estrategias o a las expectativas de la ocurrencia de comportamientos verbales corteses, por mencionar las más complejas.

En lo que se refiere a la variación intracultural, hay que mencionar, primero, que ésta corre paralela a la sociolingüística e impide generalizar modelos de cortesía verbal, incluso, dentro de una misma cultura. Algunos de sus elementos son las diferencias generacionales, las de patrones educativos, las de los roles sociales de hombres y mujeres, así como los factores socioculturales, económicos, profesionales y educativos.

Finalmente, en la individual es importante decir que cada persona construye su propia identidad lingüística tomando como base una serie de factores sociales compartidos, asimismo, existe una variabilidad subjetiva potencial (tal como el estado anímico, la emotividad o la actitud) a la hora de interpretar las señales de cortesía verbal en la comunicación.

Ante la envergadura de estas cuestiones, (re)surge una pregunta legítima, a saber: ¿Es posible introducir adecuadamente la cortesía verbal en el proceso de enseñanza-aprendizaje de EL2? 
EL PCIC

\section{Una apuesta interesante}

En este punto, la propuesta del PCIC cobra relevancia. Partiendo de un enfoque centrado en la acción - como ya lo había propuesto el MCRE—, el objetivo general gira en torno al alumno que es visto como agente social, hablante intercultural y aprendiente autónomo. En congruencia, los componentes del currículo se agrupan en cuatro grandes bloques, a saber: el gramatical, el pragmático discursivo (que es el que interesa para los fines de este artículo), el cultural y el de aprendizaje. Obviamente, esta división se establece como medida pedagógica, ya que en el desarrollo curricular los cuatro componentes se entremezclan al igual que ocurre con el uso lingüístico.

El componente pragmático discursivo —siempre con fines pedagógicos—se divide, a su vez, en tres componentes: funciones (se corresponden con las microfunciones del MCRE), tácticas y estrategias pragmáticas (que es donde concretamente está localizada la cortesía verbal), y géneros discursivos y productos textuales (o macrofunciones en el MCRE).

Las funciones se definen como el tipo de cosa que la gente puede hacer mediante el uso de la lengua, éstas se presentan como categorías y subcategorías con sus correspondientes exponentes y ejemplos ilustrativos, pero siempre desde la perspectiva de las necesidades y políticas lingüísticas europeas y, en el caso específico del español, desde la particular norma culta del castellano nor-septentrional peninsular.

Las tácticas y estrategias pragmáticas tienen como fin el uso exitoso de la lengua en contexto. Siguiendo fundamentalmente la teoría de la relevancia de Sperber y Wilson, el PcIc presenta la competencia pragmática como el conocimiento de los recursos del lenguaje para emitir (ostensión) e interpretar (inferencia) enunciados con una determinada intención comunicativa, además, de interiorizar los procesos que permitan activar las correspondientes tácticas y estrategias para el éxito comunicativo.

Como queda especificado en el propio PCIC $-\mathrm{y}$ como se mencionó en el apartado anterior-, esta concepción es una de sus principales aportaciones, ya que se presenta por vez primera a los profesionales de la didáctica del español como LA un inventario de tácticas y estrategias pragmáticas, el cual está sistematizado taxonómicamente y organizado según el MCRE. Éste será, entonces, una perspectiva integradora y generalista que intenta abarcar todos los aspectos que caben en la pragmática, en aras de la rentabilidad pedagógica. 
Así, el inventario constituye un repertorio de recursos lingüísticos y de tácticas y estrategias pragmáticas para construir e interpretar los discursos de forma apropiada en el contexto; para modalizar sus enunciados (es decir, para mostrar su actitud ante lo dicho y frente a su interlocutor); y para interactuar con otros de acuerdo con las reglas propias de cada estrategia. Ahora bien, la flexibilidad del planteamiento es tal que se especifica cómo una estrategia se puede concretar en diferentes tácticas — por ejemplo, para minimizar la imagen propia frente al otro, o bien, para usar el nosotros mayestático o la construcción impersonal se dice-y cómo una misma táctica puede responde a distintas estrategias —la repetición puede favorecer tanto la cohesión discursiva como dar énfasis a lo dicho.

El inventario se organiza en tres grandes apartados: construcción e interpretación del discurso, modalización y conducta interaccional. Cabe precisar que la negociación del significado en el aula va más allá de cualquier lista y que su relación con los aspectos socioculturales (especificados en el PCIC como"saberes y comportamientos socioculturales") es incuestionable.

\section{Relectura y adecuación necesaria}

Como ya se señaló, la novedosa propuesta del Pcıc está elaborada con base en la realidad de la política lingüística europea y en la reflexión específica de la variante del español peninsular nor-septentrional, de manera que, en su repertorio, sólo parecen las expresiones con el uso de esta variante dialectal del español general.

Igualmente, se mencionó que compartir una lengua no significa atender a usos idénticos de la misma, esto se hace evidente al comparar las variantes dialectales - diatópicas, dastráticas y diafásicas - de los 24 países en donde se usa el español como lengua de comunicación.

Así, es necesario releer y adaptar dicho plan curricular a la concreta realidad de los alumnos no hispanohablantes del CEPE, proyecto en el que estoy trabajando desde hace poco más de un año y cuyos resultados son material para otra participación.

Biblografía

Alcaraz, E. (1996) El paradigma de la pragmática. La competencia pragmática: elementos lingüísticos y psicosociales. Bilbo: Servicio editorial de la Universidad del País Vasco.

Boff, L., (1997) Columna semanal de Leonardo Boff. Agenda latinoamericana, año 1997. Brown, P. y Levinson S. (1987) Politeness. Some Universals in Language Usage, Cambridge: Cambridge University Press. 
Calvet, J. L., (2005) Lingüística y colonialismo. Breve tratado de glotofagia. México: Fondo de Cultura Económica.

Cenoz, J.y Valencia J. F. (Eds.), (1996). La competencia pragmática: elementos lingüísticos y psicosociales, Bilbo: Servicio editorial de la Universidad del País Vasco.

Escandell VIDAL, M. V. (1996). Introducción a la pragmática, Barcelona: Ariel.

HaVerKATE, H. (1994). La cortesía verbal. Madrid: Gredos.

Instituto Cervantes, (2006) Plan curricular del Instituto Cervantes. Niveles de referencia para el español. Madrid: Instituto Cervantes-Editorial Biblioteca Nueva, 3 volúmenes.

KAPUSCINSKI, R. (2001) Ébano, Barcelona: Anagrama.

RALL, M. (1999) Mañana te hablo. La deixis temporal en el acto de la promesa y su entorno cultural. Vital A. (Ed.), Paralelas, México: Universidad Nacional Autónoma de México, pp. 567-576.

Rosenblat, Á. (1970) El castellano de España y el castellano de América. Madrid: Taurus. SPERBER, D. y Wilson, D. (1994) La relevancia. Madrid: Visor. 